\title{
Sleep Characteristics of Pediatric Burn Patients
}

\author{
(1) Esra Ardahan Akgül, (1) Hatice Yıldırım Sarı \\ İzmir Katip Çelebi University Faculty of Health Science, Department of Pediatric Nursing, İzmir, Turkey
}

\begin{abstract}
Aim: Soft tissue injuries which happen because of high heat, chemicals etc. are called burns. Sleep is a complex behavior regulated by the interaction of anatomical and neurochemical areas in the central nervous system. After being burnt; patients are exposed to many stressors that cause sleep interruption and decrease sleep quality. The purpose of this study was to determine sleep characteristics, sleeplessness and sleep habits in pediatric burn patients.

Materials and Methods: This descriptive study was carried out on 96 children who were 2-6 years old in the pediatric surgery department/ burn unit for a period of between 2-7 days. For data collection, a demographic data collection form and a sleep problems characteristics and identification survey, which was created by the researchers, were used. Data were collected via face to face interviews with mothers. Questions were asked in order to compare pre- and post- burn sleep quality.

Results: Of the children, $53.1 \%$ were male and their mean age was $3.36 \pm 1.39$ years. There was a significant difference between pre- and postburn periods on children's sleeping and waking hours, total and night sleep duration, total daily sleep duration, existence of sleep interruption and number of interruptions, trouble of falling asleep and sleep latency, being tired in the morning, forcing the children to wake up and also the duration of waking up.

Conclusion: With the knowledge about the importance of sleep, attention should be paid to the sleep of children that we are providing care to. Supportive environmental regulations should be made to improve the quality of sleep in hospitals.

Keywords: Pediatrics, burn, sleep
\end{abstract}

\section{Introduction}

Pediatric burns are the third most common cause of accident-induced mortality following motor vehicle accidents and drowning (1). In the United States of America, approximately 300 children are admitted to the hospital for burn treatment and two of them die each day (2). Burn injuries lead to sudden changes in the metabolism including hypermetabolism and catabolism (3). The reasons for the increase in the metabolic rate are the effects of inflammation on the thermoregulation system after being burnt and heat loss caused by evaporation (4). If $5 \%$ or more of the total body surface area is burned in adults, this leads to an increase in the metabolic rate from $118 \%$ to $210 \%$ (5).

As in all traumas, children are more vulnerable to burn injuries than adults, which is due to physiological and anatomical differences between adults and children. Neurological systems that have not completed their development in children may not tolerate the increase in the level of norepinephrine, one of the main neurotransmitters. Children's total body surface area is more than that of adults. Accordingly, their metabolic rates are higher. Due to their thinner dermis and larger body surface area compared to those of adults, they are at 
a greater risk of developing complications in burn traumas (6).

After suffering a burn, patients are exposed to many stressors that lower sleep quality and interrupt sleep (7). Treatment-associated factors such as fixation methods, physiological factors, therapeutic interventions, diagnostic procedures, mechanical ventilation, sedatives, analgesic and anesthetic drugs are known to affect sleep. Burn patients are exposed to many environmental stimuli such as light, wound dressings, treatment alarm sounds of the devices, and sounds from infusion pumps, phones, pagers and televisions which disrupt their daily routine (8). Thermal injuries cause an increase in sleeplessness, and significant reductions in non-REM sleep (stage 3 and 4) and REM sleep (9). Typically, in burn patients, increases are observed in the metabolic rate, protein degradation and weight loss (10). Sleeplessness can increase metabolic rate and catabolism as well (11). Catabolic hormones like catecholamine and cortisol increase after the burn or sleeplessness (10). Post-burn or with sleeplessness, impaired glucose tolerance can occur too $(12,13)$; however, the amount of growth hormone decreases (14).

Although there are a lot of studies about the effects of insomnia and burns on the metabolic variables, there are only limited studies to determine sleep characteristics, sleeplessness and sleep habits. This present study was planned to determine sleep characteristics, sleeplessness and sleep habits in pediatric burn patients.

\section{Materials and Methods}

Type of Study: The study was designed as a descriptive one.

Setting: The study comprised 96 children hospitalized in the pediatric burn unit of a university hospital. As the children's burn-induced pain was intense in the first days post-burn, and because they were not expected to overcome the burn shock immediately, the data were gathered at one time between the $2^{\text {nd }}$ and $7^{\text {th }}$ days of their stay in the hospital.

Inclusion Criteria: Patients who were hospitalized at the burn clinic (but not in burn intensive care unit) for a minimum of 2 and a maximum of 7 days, between the ages of 24 and 72 months, and who had no surgery because of the burn, were conscious and whose parents volunteered to participate in the study were included in the study.

Implementation of the Study: The data of the study was collected between April 2015 and April 2016. All the parents gave their written consent before the study was started. Data were obtained with the survey method through faceto-face interviews with mothers. In order to determine the effect of the burn on sleep, the child's sleep patterns before and after burn injuries were compared. When the data were collected, questions on sleep problems were asked in such a way as to compare the child's condition prior to the burn at home, and post-burn in the hospital.

\section{Data Collection Tools}

Sociodemographic Characteristics Questionnaire: The socio-demographic Characteristics Questionnaire was developed by the researchers to collect socio-demographic data about the children in the study. The questionnaire has 28 items questioning the characteristic of the burn and the child's age.

Sleep Characteristics and Problems Identification Survey: Questions on the children's sleeplessness were prepared by the researcher through a literature review (15-18). In this survey, questions about sleep duration, the number of sleep disturbances, the causes of insomnia, the possibility of drowsiness and sleeping habits of the child were asked. The questions in the survey were asked both to determine the child's previous situation prior to the burn and post-burn. Thus, it was hoped to determine whether or not the child had a sleeping problem prior to the burn.

Ethics: This study's procedure was approved by the Institutional Review Board of İzmir Katip Çelebi University Non-interventional Clinical Studies Institutional Review Board (approval no: 2015/112). All voluntary participants were informed that they could withdraw from the study at any time at the beginning of the study. A consent form was filled out by all participants.

\section{Statistical Analysis}

The data obtained from the study were analyzed using the SPSS version 21 (2012). Participating patients' sociodemographic characteristics were given as number and percentage distributions. To analyze the mean scores obtained from the patients and their parents according to their socio-demographic characteristics, the compliance with normal distribution analysis was performed, and the dependent t-test, Friedman test and McNemar's test were used. Statistical significance was established as a $p$ value $<0.05$.

\section{Results}

The participating children's mean age was 3.36 1.39 and of the children $53.1 \%(n=51)$ were male (Table I). The part of the body exposed to burns most in the children participating in the study $(10.4 \%, \mathrm{n}=10)$ was the "hands". Of the children participating in the study, $79.2 \% \quad(n=76)$ had second-degree burns. The mean percentage of burns was $8.12 \% \pm 5.61$ (minimum: 1\%, maximum 30\%). Of the causes of burns in children, $47.9 \%$ were $(n=46)$ hot water (Table II).

There was a statistically significant difference between the durations of night sleep $(t=13.644, p<0.001)$, the times 
the children woke up $(t=10.023, p<0.001)$ and the duration of sleeps per day on pre-post burn periods $(t=8.715, p<0.001)$ (Table III).

There was a statistically significant difference between the times the children went to sleep ( $F: 12.938$, $p<0.001)$ and the number of the children who had interruptions of sleep $(p<0.001)$ and the number of the sleep interruptions in the pre- and post-burn periods ( $F$ : $55.000, p<0.001)$. There was a statistically significant difference between falling asleep patterns $(p<0.001)$, and the durations of falling asleep in the pre- and post-burn periods ( $F: 22.349, p<0.001$ ) and mothers' thoughts about having trouble while awakening the children $(p<0.001)$ and in the terms of the mothers' statements that their children had sleep problems $(p<0.001)$ (Table IV).

The sleep habits of the children in the pre-post burn periods were shown, and the pre-post burn periods were

\begin{tabular}{|l|l|l|l|}
\hline \multicolumn{4}{|l|}{ Table I. Socio-demographic characteristics of children } \\
\hline Socio-demographic characteristics & $\mathbf{n}$ & $\%$ \\
\hline \multirow{3}{*}{ Gender } & Girl & 45 & 46.9 \\
\cline { 2 - 4 } & Boy & 51 & 53.1 \\
\hline \multirow{2}{*}{$\begin{array}{l}\text { Mge, } \\
\text { Min: 2, max: } 6\end{array}$} & 2 years & 40 & 41.7 \\
\cline { 2 - 4 } & 3 years & 21 & 21.9 \\
\cline { 2 - 4 } & 4 years & 17 & 17.7 \\
\cline { 2 - 4 } & 5 years & 3 & 3.1 \\
\cline { 2 - 4 } & 6 years & 15 & 15.6 \\
\hline
\end{tabular}

Min: Minimum, Max: Maximum

\begin{tabular}{|c|c|c|c|}
\hline \multicolumn{2}{|l|}{ Characteristics } & \multirow{2}{*}{$\frac{\mathbf{n}}{10}$} & \multirow{2}{*}{$\frac{\%}{10.4}$} \\
\hline \multirow{8}{*}{ Location of burn } & Hands & & \\
\hline & Genital Area & 9 & 9.4 \\
\hline & Feet & 8 & 8.3 \\
\hline & Legs & 7 & 7.3 \\
\hline & Arms & 5 & 5.2 \\
\hline & Head & 5 & 5.2 \\
\hline & Torso & 3 & 3.1 \\
\hline & More than one body part & 49 & 51.1 \\
\hline \multirow[t]{2}{*}{ Degree of the burn } & $2^{\text {nd }}$ degree & 76 & 79.2 \\
\hline & $3^{\text {rd }}$ degree & 20 & 20.8 \\
\hline \multirow{3}{*}{$\begin{array}{l}\text { Percentage of the } \\
\text { burn } \\
\text { Mean: } 8.12 \% \pm 5.61 \% \\
\text { Min: } 1 \% \text { Max: } 30 \%\end{array}$} & $1 \%-10 \%$ & 74 & 77.1 \\
\hline & $11 \%-20 \%$ & 18 & 18.8 \\
\hline & $21 \%-30 \%$ & 4 & 4.2 \\
\hline \multirow{8}{*}{$\begin{array}{l}\text { Burn factor (cause } \\
\text { of the burn) }\end{array}$} & Water & 46 & 47.9 \\
\hline & Oil & 2 & 2.1 \\
\hline & Electricity & 1 & 1.0 \\
\hline & Stove & 4 & 4.2 \\
\hline & Flame & 6 & 6.3 \\
\hline & Tea & 30 & 31.3 \\
\hline & Food & 4 & 4.2 \\
\hline & Others & 3 & 3.1 \\
\hline
\end{tabular}

Min: Minimum, Max: Maximum

Table III. Pre- and post-burn sleep characteristics-I

\begin{tabular}{|c|c|c|c|c|c|c|}
\hline & & Mean & SD & Min-max values & $\mathbf{t}$ & $\mathrm{p}$ value \\
\hline \multirow{2}{*}{ Wake up time in the morning } & Pre-burn & 8.48 a.m. & 1.14 & $\begin{array}{l}\text { Min: } 5 \\
\text { Max: } 11\end{array}$ & \multirow{2}{*}{10.023} & \multirow{2}{*}{$<0.001$} \\
\hline & Post-burn & 6.96 a.m. & 1.09 & $\begin{array}{l}\text { Min: } 1 \\
\text { Max: } 9\end{array}$ & & \\
\hline \multirow{2}{*}{ Duration of night sleep } & Pre-burn & 10.83 hours & 1.13 & $\begin{array}{l}\text { Min: } 6 \text { hours } \\
\text { Max: } 12 \text { hours }\end{array}$ & \multirow{2}{*}{13.644} & \multirow{2}{*}{$<0.001$} \\
\hline & Post-burn & 7.44 hours & 1.79 & $\begin{array}{l}\text { Min: } 3 \text { hours } \\
\text { Max: } 12 \text { hours }\end{array}$ & & \\
\hline \multirow{2}{*}{ Duration of daytime sleep } & Pre-burn & 1.46 hours & 1.07 & $\begin{array}{l}\text { Min: } 0 \text { hours } \\
\text { Max: } 3 \text { hours }\end{array}$ & \multirow{2}{*}{-1.307} & \multirow{2}{*}{0.194} \\
\hline & Post-burn & 1.67 hours & 1.01 & $\begin{array}{l}\text { Min: } 0 \text { hours } \\
\text { Max: } 6 \text { hours }\end{array}$ & & \\
\hline \multirow{2}{*}{ Duration of daily sleep } & Pre-burn & 11.56 hours & 1.40 & $\begin{array}{l}\text { Min: } 8 \text { hours } \\
\text { Max: } 15 \text { hours }\end{array}$ & \multirow{2}{*}{8.715} & \multirow{2}{*}{$<0.001$} \\
\hline & Post-burn & 9.13 hours & 2.07 & $\begin{array}{l}\text { Min: } 4 \text { hours } \\
\text { Max: } 15 \text { hours }\end{array}$ & & \\
\hline
\end{tabular}

SD: Standard deviation, Min: Minimum, Max: Maximum 
compared from this aspect. There were statistically significant differences between the children's preand post-burn period sleep habits in the following circumstances: having difficulty falling asleep at night $(p<0.001)$, having difficulty falling asleep at night again after waking up $(p<0.001)$, taking relaxants when he/ she wakes up at night $(p=0.004)$, craving for food or drink during the night $(p<0.001)$, fear of sleeping alone $(p<0.001)$, fear of sleeping in the dark $(p<0.001)$, being anxious and restless during the day because of not having enough sleep during the previous night $(p<0.001)$, willing to be read books or listen to a lullaby before going to sleep $(p<0.001)$, feeling restless while sleeping
( $p<0.001)$, waking up screaming, crying, and waking up due to a nightmare $(p<0.001)$ (Table $V)$.

\section{Discussion}

In this study, it was found that children's mean duration of night sleep altered in the post-burn period and they went to sleep later than usual in the hospital. Similarly; Bisogni et al. (19) determined that while the number of the children who slept less than 5 hours at home increased by $4.7 \%$ after hospitalization, the number of the children who slept 9-11 hours at home decreased by 5.9\% after hospitalization (19). In the same study, the mothers put their children to sleep later in the hospital. While

\section{Table IV. Pre-post burn sleep characteristics-II}

\begin{tabular}{|c|c|c|c|c|c|c|c|}
\hline & & \multicolumn{2}{|c|}{ Pre-burn } & \multicolumn{2}{|c|}{ Post-burn } & & \multirow[t]{2}{*}{$\mathrm{p}$ value } \\
\hline & & $\mathbf{n}$ & $\%$ & $\mathbf{n}$ & $\%$ & & \\
\hline \multirow{3}{*}{ What time does the child to go to sleep? } & 7.00 p.m. -9.59 p.m. & 8 & 8.3 & 12 & 12.5 & \multirow{3}{*}{$12.938^{* *}$} & \multirow{3}{*}{$<0.001$} \\
\hline & 10.00 p.m.-11.59 p.m. & 78 & 81.3 & 43 & 44.8 & & \\
\hline & After 12 midnight & 10 & 10.4 & 41 & 42.7 & & \\
\hline \multirow{2}{*}{ Does the child have interruptions of sleep? } & Yes & 61 & 63.5 & 92 & 95.8 & \multirow{2}{*}{$*$} & \multirow{2}{*}{$<0.001$} \\
\hline & No & 35 & 36.5 & 4 & 4.2 & & \\
\hline \multirow{4}{*}{$\begin{array}{l}\text { How many times does the child have interruptions } \\
\text { of sleep? }\end{array}$} & Once & 32 & 32.5 & 5 & 5.2 & \multirow{4}{*}{$55.000^{* *}$} & \multirow{4}{*}{$<0.001$} \\
\hline & Twice & 16 & 26.2 & 13 & 14.1 & & \\
\hline & 3 times & 13 & 21.3 & 22 & 23.9 & & \\
\hline & 4 or more times & - & - & 52 & 56.5 & & \\
\hline \multirow{2}{*}{ Does the child have trouble falling asleep? } & Yes & 52 & 54.2 & 79 & 82.3 & \multirow{2}{*}{$*$} & \multirow{2}{*}{$<0.001$} \\
\hline & No & 44 & 45.8 & 17 & 17.7 & & \\
\hline \multirow{5}{*}{ How long does it take the child to fall asleep? } & Less than 15 minutes & 24 & 25.0 & 17 & 20.7 & \multirow{5}{*}{$22.349^{* *}$} & \multirow{5}{*}{$<0.001$} \\
\hline & $15-30$ minutes & 25 & 26.0 & 13 & 15.9 & & \\
\hline & $30-45$ minutes & 4 & 4.2 & 31 & 37.8 & & \\
\hline & 45-60 minutes & 4 & 4.2 & 19 & 23.2 & & \\
\hline & More than 60 minutes & - & - & 2 & 2.4 & & \\
\hline \multirow{2}{*}{ Does the child wake up tired in the morning? } & Yes & 12 & 12.5 & 58 & 60.4 & \multirow{2}{*}{ * } & \multirow{2}{*}{$<0.001$} \\
\hline & No & 84 & 87.5 & 36 & 38.3 & & \\
\hline \multirow{2}{*}{$\begin{array}{l}\text { Does the mother have trouble awakening the child } \\
\text { in the morning? }\end{array}$} & Yes & 33 & 34.4 & 55 & 57.3 & \multirow{2}{*}{$*$} & \multirow{2}{*}{$<0.001$} \\
\hline & No & 63 & 65.6 & 41 & 42.7 & & \\
\hline \multirow{4}{*}{ How long does it take to awaken the child? } & Less than 15 minutes & 22 & 66.7 & 16 & 16.7 & \multirow{4}{*}{$15.000^{* *}$} & \multirow{4}{*}{$<0.001$} \\
\hline & $15-30$ minutes & 9 & 27.3 & 34 & 35.4 & & \\
\hline & $30-45$ minutes & 2 & 6.1 & 6 & 6.3 & & \\
\hline & 45-60 minutes & - & - & 2 & 2.1 & & \\
\hline \multirow{2}{*}{$\begin{array}{l}\text { Does the mother think that the child has sleep } \\
\text { problems? }\end{array}$} & Yes & 35 & 36.5 & 78 & 81.3 & \multirow{2}{*}{$*$} & \multirow{2}{*}{$<0.001$} \\
\hline & No & 61 & 63.5 & 18 & 18.8 & & \\
\hline
\end{tabular}

*Analysis was performed with the McNemar's test. ${ }^{* *}$ Analysis was performed with the Friedman test 
Table V. Comparison of pre-post burn sleep habits

\begin{tabular}{|c|c|c|c|c|c|c|c|c|c|}
\hline \multirow[b]{3}{*}{ The child; } & \multicolumn{4}{|c|}{ Pre burn } & \multicolumn{4}{|c|}{ Post burn } & \multirow[t]{3}{*}{$\mathrm{p}$ value } \\
\hline & \multicolumn{2}{|c|}{$\begin{array}{l}\text { Never } \\
\text { occasionally }\end{array}$} & \multicolumn{2}{|c|}{$\begin{array}{l}\text { Frequently } \\
\text { every night }\end{array}$} & \multicolumn{2}{|c|}{$\begin{array}{l}\text { Never } \\
\text { occasionally }\end{array}$} & \multicolumn{2}{|c|}{$\begin{array}{l}\text { Frequently } \\
\text { every night }\end{array}$} & \\
\hline & $\mathbf{n}$ & $\%$ & $\mathbf{n}$ & $\%$ & $\mathbf{n}$ & $\%$ & $\mathbf{n}$ & $\%$ & \\
\hline Has trouble falling asleep (needs a parent) & 69 & 71.9 & 27 & 28.1 & 12 & 12.5 & 84 & 87.5 & $<0.001$ \\
\hline Has trouble falling asleep at night again after waking up & 67 & 69.8 & 29 & 30.2 & 16 & 16.7 & 80 & 83.3 & $<0.001$ \\
\hline $\begin{array}{l}\text { Wants a pacifier when he/she wakes up at night; wants his/her } \\
\text { parent to put the pacifier back to his/her mouth }\end{array}$ & 66 & 68.8 & 30 & 31.3 & 53 & 55.2 & 43 & 44.8 & 0.004 \\
\hline $\begin{array}{l}\text { Wants to drink something overnight (Sucking Mother's Breast or } \\
\text { bottle) }\end{array}$ & 86 & 89.6 & 10 & 10.4 & 68 & 70.8 & 28 & 29.2 & $<0.001$ \\
\hline Is afraid of sleeping alone & 75 & 78.1 & 21 & 21.9 & 30 & 31.3 & 66 & 68.8 & $<0.001$ \\
\hline Is afraid of sleeping in the dark & 79 & 82.3 & 17 & 17.7 & 46 & 47.9 & 50 & 52.1 & $<0.001$ \\
\hline Hugs an object while falling asleep (blanket, toy, bottle etc.) & 70 & 72.9 & 26 & 27.1 & 71 & 74.0 & 25 & 26.0 & $>0.05$ \\
\hline $\begin{array}{l}\text { Is anxious and restless during the day because of not having enough } \\
\text { sleep at the previous night }\end{array}$ & 80 & 83.3 & 16 & 16.7 & 30 & 31.3 & 66 & 68.8 & $<0.001$ \\
\hline Wants to be read books or listen to a lullaby before going to sleep & 74 & 77.1 & 22 & 22.9 & 54 & 56.3 & 42 & 43.8 & $<0.001$ \\
\hline Feels restless while sleeping & 95 & 99.0 & 1 & 1.0 & 20 & 20.8 & 76 & 79.2 & $<0.001$ \\
\hline Wakes up screaming, crying, wakes up due to a nightmare & 95 & 99.0 & 1 & 1.0 & 23 & 24.0 & 73 & 76.0 & $<0.001$ \\
\hline
\end{tabular}

the number of the children who went to sleep between 9.00 p.m. and 10.00 p.m. at home decreased by $9.8 \%$ in the hospital, the number of children who went to sleep between 10.00 p.m. and 11.00 p.m. at home increased by $10.1 \%$ in the hospital.

In this study, the participating children went to bed later, had a greater number of sleep interruptions and woke up earlier in the morning in the hospital than they did at home. Similarly, in a study by Meltzer et al. (20), children went to bed later and had more sleep interruptions in the hospital than they did at home. However, in Meltzer et al. (20) study, the children woke up later and their total sleep time increased, which was different from the results of the present study. In Setoyama et al. (21) study conducted in 2016, the parameters such as durations of the whole-day sleep, time to go to bed, wake up time, time spent in bed, sleep efficiency, sleep onset latency, the number of night waking, duration of sleep after falling asleep in the hospital were compared with those at home, and significant differences were determined between duration of sleep at night and time they spent in bed, which was similar to the results of the present study. Although statistically insignificant, when they were in the hospital, the children woke up earlier, and the duration of daytime sleep and the total daily sleep times were longer.

In this study, $82.3 \%$ of the children had trouble falling asleep after suffering a burn, and it took $37 \%$ of them $30-45$ minutes to fall asleep. Similarly, in Linder and Christian
(22) study of hospitalized children, $60 \%$ of the children experienced delays in falling asleep although they had no trouble going to bed.

In this study, $36.5 \%$ of the mothers said that their children had sleep problems at home whereas $81.3 \%$ stated that their children had sleep problems in the hospital. Similarly, in their study conducted in 2014, Orme et al. (23) compared the children's sleep characteristics at home and in the hospital, and based on the parents' statements, they determined that the children's quality of sleep was better at home.

\section{Study Limitations}

In this study, the participants were not investigated in terms of the stages of sleep. In a study conducted by Armour et al. (9), they determined that thermal burns led to increases in sleeplessness and significant decreases in non-REM sleep (stage 3 and 4) and REM sleep.

The second limitation of this study was that sleep quality indicators such as fatigue etc. were not investigated by gender. In a study by Perdikaris et al. (24), they determined that fatigue levels of hospitalized children varied by gender, and that girls' fatigue scores were higher.

The third limitation was that the relationship between sleep quality parameters and the age of the children was not investigated in the present study. In a study conducted by Price et al. (25), the duration of daytime sleep and whole day sleep decreased as the children's age increased. The other limitation was that because the children's burn- 
induced pain was intense in the first days post-burn, and because they were not expected to have overcome the burn shock immediately, the data were collected between the $2^{\text {nd }}$ and $7^{\text {th }}$ days of their stay in the hospital.

The last limitation was about the percentages of the burns. The number of patients with a percentage of burns greater than $20 \%$ during data collection was low. Different results may be obtained when studying patients with a higher percentage of burn.

\section{Conclusion}

In the current study, significant differences were determined between the participating children's pre- and post-burn conditions.

Burns cause major changes in the body metabolically. These changes generally show similar characteristics with the changes brought about by sleep deprivation. Nurses should be aware of the importance and benefits of sleep, should pay attention to sleep habits and characteristics of children they give healthcare to and make environmental arrangements to improve the quality of sleep in clinics in first week post-burn, which can minimize the triggering effect of staying in hospital on sleep disorders. It is recommended to carry out studies on the promotion of the sleep quality of hospitalized children and on changes in the effectiveness of Non-REM and REM sleep in children with burns.

\section{Key Points}

- There was a significant difference between pre-and post-burn periods on children's sleeping pattern.

- Children with a high degree of burn were shown to take longer to wake up in the morning.

- Supportive environmental regulations should be made to improve the quality of sleep in hospitals.

\section{Ethics}

Ethics Committee Approval: This study's procedure was approved by the Institutional Review Board of Izmir Katip Çelebi University Non-interventional Clinical Studies Institutional Review Board (approval number: 2015/112).

Informed Consent: A consent form was filled out by all participants.

Peer-review: Externally peer-reviewed.

\section{Authorship Contributions}

Concept: H.Y.S., E.A.A., Design: H.Y.S., Data Collection or Processing: E.A.A., Analysis or Interpretation: H.Y.S., E.A.A., Literature Search: E.A.A., Writing: H.Y.S., E.A.A.

Conflict of Interest: No conflict of interest was declared by the authors.

Financial Disclosure: The authors declared that this study received no financial support

\section{References}

1. Granger JP, Estrada CM, Abramo TJ. An evidence-based approach to pediatric burns. Pediatric Emergency Medicine Practice 2009;6:1า-22.

2. United States Centers for Disease Control and Prevention. Burns safety: The reality. http://www.cdc.gov/safechild/Burns/ index.html Accesses 15 March 2017.

3. Klein GL. Burn-induced bone loss: importance, mechanisms, and management. J Burns Wounds 2006;5:5.

4. Pereira $C T$, Murphy KD, Herndon DN. Altering metabolism. J Burn Care Rehabil 2005;26:194-9.

5. Dickerson RN, Gervasio JM, Riley ML, et al. Accuracy of predictive methods to estimate resting energy expenditure of thermally-injured patients. JPEN / Parenter Enteral Nutr 2002;26:17-29.

6. Przkora R, Jeschke MG, Barrow RE, et al. Metabolic and hormonal changes of severely burned children receiving longterm oxandrolone treatment. Ann Surg 2005;242:384-91.

7. Jaffe SE, Patterson DR. Treating sleep problems in patients with burn injuries: Practical considerations. I Burn Care Rehabil 2004;25:294-305.

8. Hinds PS, Hockenberry M, Rai SN, et al. Nocturnal awakenings, sleep environment interruptions, and fatigue in hospitalized children with cancer. Oncol Nurs Forum 2007;34:393-402.

9. Armour A, Gottschlich MM, Khoury I, Warden GD, Kagan RJ. A randomized, controlled prospective trial of zolpidem and haloperidol for use as sleeping agents in pediatric burn patients. I Burn Care Res 2008;29:238-47.

10. Mayes T, Gottschlich M. Burns and wound healing, In, Nutrition Support for the Critically IIl Patient, 2005.

11. Hipolide DC, Suchecki D, Pimentel de Carvalho Pinto A, Chiconelli FE, Tufik S, Luz I. Paradoxical sleep deprivation and sleep recovery: Effects on the hypothalamic-pituitary-adrenal axis activity, energy balance and body composition of rats. I Neuroendocrinol 2006;18:231-8.

12. Gore DC, Chinkes D, Heggers J, Herndon DN, Wolf SE, Desai M. Association of hyperglycemia with increased mortality after severe burn injury. I Trauma 2001;51:540-4.

13. Yaggi HK, Araujo AB, McKinlay JB. Sleep duration as a risk factor for the development of type 2 diabetes. Diabetes Care 2006;29:657-61.

14. Gottschlich MM, Khoury J, Warden GD, Kagan RJ. An evaluation of the neuroendocrine response to sleep in pediatric burn patients. JPEN J Parenter Enteral Nutr 2009;33:317-26.

15. Johns MW. Reliability and factor analysis of the epworth sleepiness scale. Sleep 1992;15:376-81.

16. Owens JA, Spirito A, McGuinn M. The children's sleep habits questionnaire (CSHQ): Psychometric properties of a survey Instrument for school-aged children. Sleep 2000;23:1043-51.

17. Chervin RD, Hedger K, Dillon JE, Pituch KJ. Pediatric sleep questionnaire (PSQ): Validity and reliability of scales for sleepdisordered breathing, snoring, sleepiness, and behavioral problems. Sleep Medicine 2000;1:21-32.

18. McGreavey JA, Donnan PT, Pagliari HC, Sullivan FM. The tayside children's sleep questionnaire: A simple tool to evaluate sleep problems in young children. Child Care Health Dev 2005;31:53944.

19. Bisogni S, Chiarini I, Giusti F, Ciofi D, Poggi GM, Festini F. Impact of hospitalization on the sleep patterns of newborns, infants and toddlers admitted to a pediatric ward: A cross-sectional study. Minerva Pediatr 2015;67:209-17. 
20. Meltzer LI, Davis KF, Mindell JA. Patient and parent sleep in a children's hospital. Pediatr Nurs 2012;38:64-71.

21. Setoyama A, İkeda M, Kamibeppu K. Objective assessment of sleep status and its correlates among hospitalized children with cancer: An exploratory study. Pediatr Int 2016;58:842-9.

22. Linder LA, Christian BJ. Nighttime sleep characteristics of hospitalized school-age children with cancer. I Spec Pediatric Nurs 2013;18:13-24.

23. Orme LM, Babl FE, Barnes C, Barnett P, Donath S, Ashley DM. Outpatient versus inpatient IV antibiotic management for pediatric oncology patients with low risk febrile neutropenia: A randomised trial. Pediatric Blood Cancer 2014;61:1427-33.

24. Perdikaris P, Merkouris A, Patiraki E, Papadatou D, VasilatouKosmidis $\mathrm{H}$, Matziou V. Changes in children's fatigue during the course of treatment for paediatric cancer. Int Nurs Rev 2008;55:412-9.

25. Price AM, Brown JE, Bittman M, Wake M, Quach J, Hiscock $\mathrm{H}$. Children's sleep patterns from 0 to 9 years: Australian population longitudinal study. Arch Dis Child 2014;99:119-25. 